\title{
Didactismo y moralidad en la labor de traducción de Joaquina García Balmaseda (1837-1911)
}

Palabras clave: traducción, didactismo, censura, escritoras, traductoras

Joaquina García Balmaseda (1837-1911) es hoy en día una escritora conocida por sus contribuciones a la literatura y el periodismo de mediados del siglo XIX. Existen muchas referencias a su producción literaria y a sus colaboraciones en revistas femeninas de la época, diseminadas en artículos y capítulos de libros; sin embargo, su labor como traductora no ha sido tan estudiada. El inmenso catálogo de traducciones de Balmaseda pone de relieve la importancia que tuvo esta parcela en su propia obra y, a la vez, muestra cómo contribuyó a divulgar los escritores europeos más importantes de su tiempo (George Sand, Paul Féval, Alexandre Dumas y Wilkie Collins, Charles Dickens y Mary Elizabeth Braddon entre otros). García Balmaseda ejerció un papel muy importante como mediadora cultural, sobre todo, en La Correspondencia de Espa$\tilde{n} a$ (1860-1925), revista en la que colaboró asiduamente con sus traducciones. Destaca la inmediatez con la que tradujo las obras, lo dificultoso que resultaba trasladar y acortar novelas de grandes dimensiones para acomodarlas a la prensa. Ahora bien, sus convicciones ideológicas se hallan en el germen de sus producciones literarias y de traducción. En estas, suprime partes que no considera apropiadas para el lector de la época; modifica el argumento y lo acomoda para que forme parte de esa «literatura edificante» tan propia de la época isabelina. En la mayoría de los casos, las supresiones o cambios afectan a cuestiones políticas, morales y religiosas, a expresiones contrarias a la tradición, matrimonio, familia o valores de la patria. 


\section{Introducción}

El contexto de la sociedad española del siglo XIX estaba regido por una marcada división binaria de los dos sexos: el público para el varón y el doméstico para las jóvenes. A pesar de estas limitaciones, y desde las distintas plataformas sociales y culturales en las que se inscribían las mujeres, se manifestó la insatisfacción y la necesidad de cambios en los diferentes órdenes de la vida. A partir del año 1840 , época en que tanto la estética romántica como el reformismo liberal se imponen brevemente, empiezan las españolas a publicar. Efectivamente, y como bien ha señalado Josefina de Andrés Argente (2007: 49), desde las páginas de periódicos, libros y revistas femeninas dirigidas a la burguesía acomodada, mujeres de diferentes niveles de conciencia realizarán un trabajo sistemático para hacer visibles algunos de los problemas de sus contemporáneas.

De este modo, las revistas eran los cauces donde las mujeres se daban a conocer; convirtiéndose en colaboradoras, redactoras, directoras y responsables de secciones fijas ${ }^{1}$. Además, los diarios de la época requerían el trabajo a destajo de numerosos traductores que tenían que verter al español muchas obras de literatura francesa. Con la incorporación de la mujer a la escritura gracias al desarrollo de la prensa escrita, fueron muchas las jóvenes que se dedicaban a la traducción ${ }^{2}$. Esta práctica constituía, asimismo, por parte de los editores, una forma de responder con agilidad a la demanda de un mercado en expansión y de adaptarse a los gustos de los lectores, particularmente en el caso de géneros nuevos y muy solicitados, como la novela sentimental, los folletines y los cuentos. De acuerdo con lo planteado por Francisco Lafarga (2005: 186), la labor traductora, enfrentada o confrontada con la labor creadora, ofrecía un abanico bastante amplio de opciones y realidades: desde el caso de la autora, de nombre poco conocido, de la que no se conoce nada de la obra, hasta el de la escritora consagrada, que aparece en los manuales de historia de la literatura y que además se dedicó a traducir. En este sentido, la traductora es una mujer

1 De acuerdo con lo planteado por Susan Kirkpatrick: «Después de 1840, la industria editorial procuraba aumentar su mercado llevando las producciones de las plumas femeninas a un público lector general que incluía cada vez más mujeres. En la segunda mitad del siglo surgieron revistas especializadas para mujeres que proporcionaron una salida amplia para la creación literaria femenina» (1992:13).

2 Según María del Carmen Simón Palmer: «Es digno de elogio el esfuerzo de aquellas que aprenden idiomas sin salir de casa y que gracias a sus traducciones facilitan el conocimiento de novelas hasta entonces inéditas en España. Bien es cierto que otras son grandes viajeras, como Sofia Casanova, que nos acercó a autores como Kowalewska o Sienkiewich. Los autores franceses son los más traducidos, pero no faltan los ingleses e italianos» (1991: XII-XIII). 
que lucha por su autonomía personal y profesional, de esmerada educación, que mantiene relaciones sociales con otras intelectuales y con la política de ese momento. Entre estas jóvenes se encuentra la labor realizada por Joaquina García Balmaseda, escritora, directora de varias revistas y también traductora.

\section{Joaquina García Balmaseda: vida y obra}

En la actualidad poseemos pocos datos sobre su vida. Balmaseda nació el 17 de febrero de 1837 en Madrid en el seno de una familia humilde. Desde pequeña, sus padres le inculcaron el amor por la literatura y las letras, llegando a confesar: «La lectura ha sido la pasión de mi espíritu... ¡Cuántas lecturas que fueron en mi infancia recreo de mis padres, se han convertido en manantial de conocimiento, señalándome estudios que nunca hubiera soñado!» (García Balmaseda, 1880 : 123). Su carrera y sus intereses intelectuales fueron muy diversos y nada comunes para una mujer de su tiempo: estudió declamación y música en el Conservatorio de Madrid y a los catorce años debutó en el Teatro Español. Posteriormente, inició su carrera como actriz profesional en la Compañía Teatral de Joaquín Arjona, donde aprendió las rúbricas del arte dramático y más tarde le serviría para publicar los dramas Genio y figura (1861), Donde las dan... (1868) y Un pajarito en el garlito (1871).

García Balmaseda fue una escritora con luces y sombras, ya que como bien ha perfilado Ana María Gómez-Elegido Centeno (2014), define la misión de la mujer cuyo norte es la familia, pero también reivindica la importancia de la instrucción para procurar el desarrollo propio e independiente de las jóvenes $^{3}$. De esta manera, en sus obras pone en evidencia el gran retraso en el que vivían las mujeres de su época y, a la vez, resalta la importancia de una buena educación para así atender a las materias propias del «bello sexo». Otras veces, revela la lucha interna entre el deseo de independizarse y seguir su vocación profesional, y el de casarse y dedicarse por completo a la familia. En el Correo de la Moda. Album de Señoritas señalaba así el objetivo de sus escritos:

Si al terminar penosa, aunque agradable tarea, hemos conseguido instruir a unas, perfeccionar a otras en un nuevo género

3 En la época de García Balmaseda se abre un importante debate en el que los más conservadores esgrimen el argumento de la virtud para rechazar las ambiciones literarias de las escritoras, mientras que otros aceptan la escritura femenina siempre y cuando se mantenga en ciertos límites que no son otros que la sensibilidad y lo doméstico. Como bien ha señalado Isabel Navas Ocaña: «se sientan así las bases de lo que se ha llamado la ideología de la domesticidad o el modelo femenino del ángel del hogar» (2009: 153). 
de labor, y excitar en todas la laboriosidad y afición al trabajo, base de las virtudes domésticas de la mujer, se verá cumplido nuestro deseo y habremos contribuido con nuestro grano de arena al edificio de la felicidad pública (García Balmaseda, 1860: 6)

Joaquina García Balmaseda fue una joven activa e intelectual que tuvo una gran acogida entre los lectores de su época. Impartió conferencias, charlas y dirigió en 1869 la sección de labores en el Ateneo de Señoras presidido por la también escritora Faustina Sáez de Melgar4. Además, fue la primera mujer que participó en una serie de presentaciones en la Universidad Central de Madrid, aunque fuera simplemente para recitar un poema «Flores y aves». En cuanto a su obra, podríamos decir que es muy amplia y que abarca todos los géneros posibles: manuales y libros de instrucción femenina, poemas, proverbios, cartas, leyendas, relatos y dramas. Entre estas destaca: La madre de familia (1860), Diálogos instructivos sobre la religión, la moral y las maravillas de la naturaleza (1868), Entre el cielo y la tierra (1868), La mujer laboriosa (1876), La mujer sensata (1882), Consejos útiles para la mujer y leyendas morales (1882), Historia de una muñeca, escrita por ella misma (1889) y Ecos de otra edad (1906). En todos estos textos, la autora siempre añadía un prólogo explicando los motivos por los que escribía, siempre en sintonía con los dogmas morales de su tiempo. Así en el manual La mujer sensata señalaba:

Diré, no obstante, en elogio de mi libro, que está escrito, no para desentrañar una cuestión social ni hablar a los hombres de mejorar la condición de la mujer, que es el objeto de la mayor parte de los libros que de la mujer tratan; está escrito para la mujer: para que ésta pueda educarse a sí misma y a sus hijos; para que ésta encuentre en su propia docilidad e instrucción el secreto de su dicha hasta donde puedan permitirlo el carácter y las circunstancias que la rodean (García Balmaseda, 1882: 6).

4 Faustina Sáez de Melgar comenta en su artículo: «Ateneo artístico y literario de señoras»: «No ha transcurrido todavía un mes desde que mi primer artículo sobre el Ateneo apareció en las columnas de La Iberia y son ya numerosas las señoras que, como socias, como alumnas y como profesoras, han acudido apresuradas a inscribir sus nombres en las listas de tan benéfica asociación» (1869: 2). Melgar indicaba también el objetivo del Ateneo de Señoras, educar a las mujeres para que a su vez pudieran instruir a sus propios hijos. De hecho, según los estatutos de esta asociación, no se reclamaban los mismos derechos que los hombres, ni tampoco se abogaba por la emancipación y liberación de la mujer, como estaba ocurriendo en otros países europeos. 
En cuanto al clima intelectual de la época, García Balmaseda se benefició de un contexto cultural favorable con el desarrollo de la alfabetización, la liberación de la prensa, el crecimiento de las ciudades y las vías de transporte, factores que explican un aumento de la demanda de la letra impresa ${ }^{5}$. Los periódicos desempeñaron un papel importante: le proporcionaron un sueldo más seguro y regular que la venta hipotética de un libro y la acercaron a un público más amplio. De esta forma, desde 1857, Balmaseda se dedicó a escribir en la prensa española artículos, cuentos y ensayos de temática en torno a la mujer. La autora colaboró en numerosos periódicos como La Educación Pintoresca (1857-1859), La Aurora de la Vida (1861), La Educanda (1862-1865), La América (1862), El Museo Literario (1863-1865), La Violeta (1868), El Recreo de las Familias (1869-1870) y La Voz de la Caridad (1870), revistas donde subyace un interés por promover la educación de la mujer. También contribuyó activamente en obras colectivas como fueron Las mujeres españolas, lusitanas, pintadas por sí mismas (1881) por medio de dos artículos «La actriz española» ${ }^{6}$ y «La chula madrileña», y en El Almanaque Bastinos y Escritoras españolas (1887). En cuanto al contenido de estas publicaciones, combina los aspectos reformadores y los tradicionales; defiende tanto la reclusión de la mujer en el hogar, como su presencia en la esfera pública.

Además, Balmaseda inauguró la Biblioteca del Correo de la Moda con el Álbum de señoritas que era un tratado sobre costura, ganchillo y bordado. En todo caso, esta publicación fue una de las revistas más representativas y longevas de la prensa española dedicada a la moda al mismo tiempo que a la literatura, al teatro y a promover la emancipación de la mujer a través de la educación. En ella se dio cita un dilatado y destacado número de escritoras que iniciaron sus carreras literarias e intelectuales durante esta época: Rosario de Acuña (18501923), Concepción Gimeno de Flaquer (1850-1923) y Blanca de los Ríos de Lampérez (1862-1956).

5 Según Jean-François Botrel: «A lo largo del siglo XIX, España conoce importantes progresos de la aptitud teórica para la lectura: después de la vertiginosa regresión de las tres primeras décadas, en relación con un crecimiento demográfico superior y una creciente urbanización, se produce una dinámica de alfabetización acelerada durante el último cuarto del siglo: de unos 600.000 alfabetizados, en los años 1800 , se llega a unos 3.000 .000 de españoles que saben leer y escribir en 1860.» (1996: 239)

6 En «La actriz española» Joaquina García Balmaseda abogaba por aquellas que se dedicaban al teatro y a las representaciones escénicas: «Mujeres que han vivido familiarizadas con el arte en una época en que aún no se admitían difícilmente a la mujer artista, teniendo que procurarse una educación literaria después de conquistar triunfos en la escena, porque la educación de la mujer era harto limitada cuando ellas recorrieron los senderos de la infancia, han tenido que vivir para el estudio del arte que tenían que enaltecer, y en el retiro que les imponía la clase que tenían que acreditar» (1881: 72). 


\section{La labor de traducción de Joaquina García Balmaseda}

Como previamente se ha indicado, García Balmaseda ejerció un papel muy importante como traductora, sobre todo, en La Correspondencia de España (1860-1925). Sus colaboraciones en esta revista se inician en 1861 y se extienden hasta principios de la década de los ochenta, cuando, a la muerte de Ángela Grassi, asume la dirección de El Correo de la Moda ${ }^{7}$. Esta publicación fue la primera que inició el periodismo de empresa en España, estrictamente informativo e independiente de los partidos políticos. La Correspondencia alcanzó gran popularidad como un diario donde aparecían noticias sobre modas, ecos de sociedad, deportes, folletines, novedades literarias y también traducciones de obras extranjeras. Entre los autores que vertió al español en este periódico se encuentran: Charles Reybaud (1861), Henri Rivière (1862), Xavier Boniface Saintine (1862), Virginie Ancelot (1863), Henri Conscience (1863), Auguste Maquet (1863), Charles Deslys (1867), Pierre Alexis Ponson du Terrail (1868), Paul Féval (1870), Solange Clésinger-Sand (1871), Louis Enault (1872), Ernest Feydeau (1873), Fortuné du Boisgobey (1873), Wilkie Collins (1874), Charles Dickens (1875), Alphonse Daudet (1877), Georges Ohnet (1881) y George Sand (1888).

La prensa se transforma en un lugar de encuentro entre el texto traducido, la crítica, la publicidad y las ilustraciones destinadas a clases burguesas, urbanas y acomodadas que participan activamente en la importación y exportación de nuevas pautas de comportamiento y de pensamiento ${ }^{8}$. Entre aquellos que colaboraban con traducciones en La Correspondencia de España se hallaban profesionales de gran prestigio como José Lesen y Moreno que tradujo los Cuentos inéditos de Edgar Allan Poe o Joaquín María de Tejada que virtió al español

7 En 1883, Joaquina se casó con Eustacio González Marcos, profesor de Veterinaria y colaborador de algunos periódicos militares. La escritora rompió con todas las convenciones de la época, contrajo matrimonio a los cuarenta y seis años, y continuó escribiendo, traduciendo y colaborando en la prensa, aunque a partir de esas fechas su firma aparecerá como Joaquina García Balmaseda de González. Ese mismo año, García Balmaseda pasó a dirigir El Correo de la Moda, tarea que desempeñó hasta 1893.

8 Según Carmen Ramírez Gómez: «La frecuencia y la recurrencia de Balmaseda en los medios periodísticos de su tiempo convierten a la prensa en el archivo mayor de su biografía, y de sus trabajos de escritura, entre los cuales se multiplican sus traducciones, casi sepultadas entre consejos, ficciones y artículos varios. Novelas traducidas, de menor fortuna editorial, que vertebran, sin embargo, uno de los pilares de su intenso trabajo de lectura y escritura. La traductora Balmaseda se forja y afianza precisamente en los dominios de la prensa tanto por el género traducido (el folletín) como por el modo editorial y las vías de recepción» (2016: 391). 
la novela gótica Julia de Ann Radcliffe9. Entre las mujeres que trasladaban obras en esta revista se encuentra una nómina de autoras bien conocidas en el mundo literario del momento como Julia Codorniu y Pilar Sinués de Marco. Esta última escritora, y como bien ha señalado Helena Establier (2015: 74), inserta tres traducciones en años consecutivos: La caballera de Paul Féval, Dos bistorias verdaderas de Matilde Bourdon y unos cuadros sociales titulados $\mathrm{La}$ escala del dolor.

De este modo, entre 1861 y 1880 , muchas de las traducciones de La Correspondencia de España las realiza García Balmaseda. En la mayoría de los casos firma con su nombre, otras veces con sus seudónimos «Aurora Pérez Mirón», «Baronesa de Olivares», «Adela Samb», «Lady Kitty» y «Zahara», y, en algunas ocasiones, solamente con sus iniciales ${ }^{10}$. En lo que se refiere al formato, o bien aparecen en la revista por medio de entregas, o bien en un número especial que se regalaba a aquellos suscriptores de La Correspondencia de España, como fueron Dos para dos (1861) de Reybaud, Un ruiseñor cogido en el garlito (1862) de Saintine y El primer amor de una niña (1862) de Lardine y Mie d'Aghone.

En cuanto al tipo de obras que traduce en La Correspondencia de España, son prácticamente novelas y folletines de temas muy diversos. María del Carmen Simón Palmer (1991) llega a la conclusión de que buena parte de estas traducciones buscaban el éxito comercial por algún escándalo en el extranjero o por las numerosas ventas que precedían a la obra en el país de origen, aunque también existía la intención de dar a conocer en España la literatura europea a través de la publicación cuidada de una selección de autores de prestigio. De esta manera, se produce así la popularización de novelas en serie; las obras dejan de publicarse en lujosos ejemplares encuadernados en piel y los periódicos se convierten en el vehículo de la mejor ficción del siglo XIX. El feuilleton, acerca al lector a la literatura más accesible y popular, y además, tiene repercusiones en el ámbito de la escritura y la traducción. También, el periódico exige una

9 Según Miriam López Santos (2015: 269), Ann Radcliffe tuvo gran éxito en España. Sus novelas arrasaban entre los lectores de la época y aparecieron multitud de traducciones como: Adelina o La abadía en la selva (Romance of the Forest, 1791), junto con las ediciones de Los misterios de Udolfo (The Mysteries of Udolfo, 1794), Julia o Los subterráneos del castillo de Mazzini (A Sicilian Romance, 1790).

10 Según María del Carmen Simón Palmer (1991: XV), el hecho de participar en una tarea como la literaria, que incluso en el siglo XIX se consideraba como masculina, coartaba la iniciativa femenina y suponía una continua justificación de su conducta. De esta manera, trataban de esconder su personalidad bajo un nombre y apellidos falsos para así no ser reconocidas por el público lector. 
estructura narrativa simple y, al mismo tiempo, una organización de material en suspense que permita al lector recuperar la narración con la misma pasión con la que se había abandonado. Carmen Ramírez Gómez (2015: 69) señala que el repertorio de Balmaseda comprende una etapa de la historia literaria francesa, referida a la novela popular y al folletín en particular, cuyo ambiguo estatus poético la sitúa en la confluencia de diversos movimientos ideológicos y literarios combinando posromanticismo, costumbrismo, novela policiaca y naturalismo. También resulta curioso que algunas de las traslaciones fueron realizadas por primera vez en España y también que algunas de ellas carecen de una versión contemporánea.

Además, Balmaseda traducía a un ritmo frenético marcado en parte por la rapidez con la que se publicaban las revistas. Estas traducciones folletinescas se realizaban con gran celeridad para que las entregas de la versión española coincidiesen prácticamente con las del texto original ${ }^{11}$. Según Carmen Ramírez Gómez (2016: 396), el mérito de la escritora es haber podido mantener el ritmo de la escritura por entregas, ya que García Balmaseda tradujo de modo interrumpido durante dos décadas y media, una media de dos obras anuales y, en ocasiones, entre cinco y ocho traducciones por año en la década de 1860.

Las traducciones de Balmaseda provienen del francés, del inglés y del italiano, aunque se cree que utilizó versiones intermedias, como el francés, lengua de mediación cultural durante el siglo XIX. De hecho, en la traslación de Marido $y$ mujer (1874) de Wilkie Collins, su versión incluye galicismos como paquebot, cuando el término más adecuado sería «barco»:

On a summer's morning, between thirty and forty years ago, two girls were crying bitterly in the cabin of an East Indian passenger ship, bound outward, from Gravestand to Bombay» (Collins, 2016: 3).

Una mañana de verano, sobre las olas... en el camarote de un paquebot de la compañía de las Indias orientales, que se disponía a partir desde Graveland para Bombay, dos hermosas jóvenes lloraban (Collins, trad. de García Balmaseda, 1874: 5).

11 «Esta singular escritora-traductora-adaptadora añade a la labor de recuperación y conservación que implica la traducción, la intensa labor de renovar, diversificar y actualizar el panorama de las novelas por entregas, aunque fuera desde la sospechosa cultura narrativa francesa por un lado, y la no menos históricamente denostada labor traductora por otra.» (Carmen Ramírez Gómez, 2015: 67) 
Otro aspecto relacionado con las traslaciones de García Balmaseda es que se tienen que acomodar al espacio de los diarios, es decir, la traductora tuvo que hacer muchos ajustes, recortes y supresiones del argumento, para poder adaptarlo a este tipo de publicaciones periódicas. Así en la novela Man and Wife de Wilkie Collins, suprime frases redundantes con la intención de agilizar el diálogo, como puede observarse en el siguiente fragmento:

Don't bring her up like me! She must be a governess -she must get her bread- Don't let her act! Don't let her sing! Don't let her go on stage! she stopped -her voice suddenly recovered it sweetness of tone - she smiled faintly- she said the old girlish words once more, in the old girlish way «Vow it Blanche!» Lady Lundie kissed her, and answered, as she had answered when they parted in the ship «I will do it Anne» (Collins, 2016: 18).

¡No la eduquéis como a mí me educaron! murmuró -que sea institutriz, que gane su vida... pero no en el teatro y no la dejéis salir a un teatro... se detuvo: su voz era cada vez más débil. Sonrió dulcemente, y con el cariño infantil de otros días murmuró: «jJuradlo Blanca!» (Collins, trad. de García Balmaseda, 1874: 12).

Efectivamente, las políticas de colecciones y de traducciones, como bien ha indicado Juan Crespo (2007: 52), tuvieron aspectos negativos provocados por la mecánica misma de una colección por suscripción sometida a plazos cortos y fechas de entregas fijas. De hecho, este sistema obligaba a traducir a destajo y en cadena para lanzar al mercado traslaciones de muchas plumas en varios volúmenes, repletas de errores y erratas. En cuanto al método de traducción de Balmaseda, podríamos decir que existe una convergencia entre traslación y adaptación, que implica en muchos de los casos una reescritura de los textos originales. En este sentido, puede afirmarse que las versiones españolas se presentan con partes resumidas, supresiones y reescrituras, con palabras e ideas añadidas e, incluso, equivocaciones en cuanto al sentido de ciertas frases o palabras. De esta manera, la traductora española modifica los títulos de las obras, así la novela Poor Miss Finch de Wilkie Collins, lo traduce por ;Pobre Lucila! (1878) en vez de la versión La pobre señorita Finch, o la obra The New Magdalen de Wilkie Collins termina bajo la versión La muerta viva (1876). También elimina prólogos o acorta muchas partes como ocurrió en la introducción de $M a-$ rido y mujer (1874): «Eliminó los fundamentos que habían motivado la composición de dicha novela, así como los rasgos de idiosincrasia que Collins exponía 
para justificar su obra y sus opiniones sobre las leyes del matrimonio vigente» (Thion Soriano-Molla, 2015: 443) ${ }^{12}$.

Además, hay que tener en cuenta que la escritora se vio condicionada por la severidad de la censura como la «Ley de Imprenta de 1879» que otorgó a los censores el poder absoluto para controlar los medios de comunicación, de tal manera que los escritores y periodistas se vieron sometidos a la línea ideológica de los gobernantes (María López de Ramón, 2006: 13). Teniendo en cuenta este contexto, García Balmaseda retoca sus traducciones; suprime partes que pueden causar escándalo y añade elementos más propios de la cultura española. Así en La muerta vida, elimina partes comprometedoras, como el pasado de Mercy Merrick, una joven que había ejercido la prostitución. En la versión de Balmaseda, no se alude en ningún momento a estas mujeres como «sinning fellow-creatures»o «fallen women», sino que más bien se refiere a ella como una «desgraciada criatura» o una «mujer abandonada»:

«Have you ever read of your unhappy fellow creatures (the starving outcast of the population) whom Want has driven into Sin?’»

Still wondering, Grace answered that she had read of such things often, in newspapers and in books. «Have you heard -when those starving and sinning fellow-creatures happened to be women -of Refugees established to protect and reclaim them?»

The wonder in Grace's mind passed away, and a vague suspicion of something painful to come took its place (Collins, 2016: 19).

-Leeréis periódicos, como todo el mundo, ¿No es verdad? ¿No habéis leído en ellos alguna vez la historia de esas desgraciadas criaturas muertas de frío, rechazadas por todos? Gracia, cuyo asombro era creciente, recordó en efecto haber leído algo de aquello en periódicos y libros.

12 Joaquina García Balmaseda incorporó la introducción a la obra de Marido y mujer, pero eliminó parte del contenido, quedando reducido a una página, frente a las tres del original: «El episodio que hoy someto al lector, difiere de todas mis obras anteriores. La ficción esta vez se apoya en hechos y trata de servir de apoyo para corregir abusos sin razón tolerables. No puede haber discusión sobre la escandalosa legislación que rige para el matrimonio en Reino Unido; el informe de la comisión real, nombrada para estudiar la aplicación de estas diversas leyes ha servido de fundamento para este libro» (1874:4). 
-Y si esas pobres criaturas son mujeres abandonadas, ¿ No habéis oído hablar de asilos, de refugios que las recogen para encaminarlas hacia el bien? Gracia, que estaba atónita, concibió la horrible certidumbre de que iba a escuchar una historia dolorosa. (Collins, trad. de García Balmaseda,1876: 8).

También en ¡Pobre Lucila! de Wilkie Collins, lo que en inglés es una referencia a dos hombres que lloran y se besan efusivamente, en la versión española los jóvenes se abrazan, resultando en una escena mucho más acorde con la moralidad de la época:

The parting between them was most affecting. The brother who spoke to us tonight insisted on it -or the other would have refused to leave him. They both shed tears-.

«They did worse than that» said old Zillah, re-entering the room at that moment. «I have made all the doors and windows fast downstairs; he can't get in now, my dear, if he tries» «What did they do that was worse than crying?» I inquired.

«Kissed each other!» said Zillah, with a look of profound disgust. Two men! Foreigners, of course.» «Our man is no foreigner» I said (Collins 2009: 19).

-Partió aquel mismo día. Su despedida fue muy tierna y el que nos ha hablado esta tarde, insistió mucho para que no se marchase el otro y dice que lloraron los dos.

-Hicieron algo peor, - dijo la vieja Zillah que entraba:-en fin, ya he hecho cerrar por abajo puertas y ventanas y le será difícil penetrar aunque lo intente.

- ¿Y qué hayáis de reprensible en que llorasen? -pregunté a la nodriza.

${ }_{-}$¿Es que se abrazaron! ¡Abrazarse dos hombres! Bien se conoce que no son ingleses (Collins, trad. de García Balmaseda, 1878: 11).

De esta manera, también en La muerta viva (1876), cuya versión original es The New Magdalen, se narra la historia de Mercy Merrick, una muchacha de la calle que asume una falsa identidad y posteriormente se casa con Julian Gray, un clérigo anglicano. En el paratexto que acompaña la traducción, García Balmaseda justifica los procedimientos que ha seguido a la hora de trasladar la obra de Wilkie Collins, es decir, los cambios que ha realizado en el texto: 
En esta obra, rica en situaciones dramáticas, admirable por lo bien delicado de sus caracteres, me he permitido algunas alteraciones, creyendo que sin ellas podía ofender a alguna clase muy respetable de nuestra sociedad: variar, pues, la condición de un personaje y abreviar algunas situaciones que se arrastraban lánguidas, son las licencias que me he permitido, y como a mi juicio, las copias valen más cuanto más al original se parecen, cumple a mi lealtad confesar mi falta, que acaso aparecerá disculpable en gracia de intención (Collins, trad. de García Balmaseda, 1876:4).

De este modo, en La muerta viva, la traductora reduce considerablemente el argumento; elimina muchas descripciones, e incluso altera el contenido. Así transforma a Mercy Merrick, una joven descarriada, en una mujer completamente arrepentida de su pasado, pura y virtuosa. Incluso suprime muchas frases del texto original:

A woman who has lived my life, a woman who has suffered what I have suffered, may love you -as I love you- but she must not be your wife. That place is too high above her. Any other place is too far below her and below you (Collins, 2016: 240).

Después de haber vivido como usted sabe, después de haber padecido tanto, puedo quererlo a usted y le quiero de veras, pero no puedo ser su mujer. No merezco esa felicidad» (Collins, trad. de García Balmaseda, 1876: 128).

Asimismo, en el capítulo XVII, cuando Mercy se arrepiente de su vida pasada y se produce el encuentro amoroso con Julian Gray, la traductora recorta escenas no apropiadas para la época, como la frase: «While she was almost in his arms, while her bosom was just touching his»:

She attempted to throw herself on her knees at his feet. He sprung from his seat and checked her, holding her as he rose himself. In the words which had just escaped her, in the startling action which had accompanied them, the truth burst on him. The guilty woman had spoken of herself! While she was almost in his arms, while her bosom was just touching his, before a word more had passed his lips on hers, the library door opened. Lady Janet Roy entered the room (Collins 2016: 118). 
Iba a arrodillarse delante de él, pero Julián, la levantó sosteniéndola en sus brazos. Las últimas palabras de Mercy, el movimiento súbito que las había acompañado, le hicieron ver pronto la verdad, la verdad terrible. Aquella mujer culpable era la que tenía delante. Antes de que saliera una palabra de los labios de Julián o de Mercy, que estaban casi abrazados, se abrió la puerta de la biblioteca, y entró Lady Janet (Collins, trad. de García Balmaseda, 1876: 99).

Además, la versión española adquiere un tono más religioso y acorde al catolicismo. En el capítulo XXVII, que en inglés se titula: «Magdalen's Apprenticeship», en español se transforma en «Noviciado de Magdalena», «the matron» es traducido como «la superiora», «curate» como «eclesiástico»y «refuge» como «convento»:

The matron, on receiving me into the Refuge, frankly acknowledged that there were terrible obstacles in my way (Collins, 2016: 190).

La superiora, al recibirme en el convento, me había advertido francamente de que tendría que tropezar con grandes obstáculos (Collins, trad. de García Balmaseda, 1876: 167).

You forget that I am a curate. Curates are privileged to make themselves useful to young ladies. Let me try (Collins, 2016: 220).

¿Quiere usted que la ayude a arreglarlos? Los eclesiásticos debemos prestar nuestro auxilio a quien lo necesite (Collins, trad. de García Balmaseda, García Balmaseda, 1876: 193).

\section{La traducción de autores europeos del siglo XIX}

Como previamente hemos señalado, entre los muchos escritores que tradujo Joaquina García Balmaseda destaca Paul Féval, periodista, fundador de varios periódicos y presidente repetidas veces de la Societé des Gens de Lettres. Féval publicó más de cien novelas autobiográficas, fantásticas, históricas, sociales, políticas y de capa y espada ${ }^{13}$. La primera traducción de ellas fue El jorobado (1861), y

13 Paul Féval (Rennes, 1816-París, 1887) empezó a escribir para la prensa en 1837 y a gozar de alguna fama literaria con Les mystères de Londres, publicado en 1843 con el seudónimo de Sir Francis Trollop. Después de su conversión al catolicismo militante, modificó muchas de sus novelas originales, eliminando todo lo que no fuera apropiado. 
a partir de esa fecha, Balmaseda vertió al español un gran número de obras del escritor de Rennes: La guardia negra (1862), Los bábitos negros (1864) -que es la primera de las ocho obras de «Misterios urbanos»-, Los vagabundos nocturnos (1865), El paraíso de las mujeres (1874), Los cinco (1876), El pescado de oro (1876) y La duquesa de Nemours (1882). El jorobado fue sin duda alguna la novela que consagró a Balmaseda como traductora de grandes obras y de escritores de primera línea. Jean-François Botrel (2009: 387) constata que este relato convirtió al escritor francés en el referente imprescindible de la novela popular francesa, junto a Dumas y a Paul de Kock, y se publicaron casi cien traducciones de sus novelas, sin olvidar, después de 1876, Las etapas de una conversión y iJesuitas!. De hecho, el prestigio que alcanzó este autor francés en el panorama literario español decimonónico se debe en parte a las traslaciones que realizó la propia Balmaseda de sus numerosísimas obras, siendo la primera en traer a la luz estos folletines que más tarde serían traducidos por profesionales como Víctor Balaguer, Francisco de Orellana y Pilar Sinués de Marco entre otros.

Aunque la mayoría de los autores que vertió al español eran franceses, también se encuentran unos cuantos británicos, como fueron: Wilkie Collins (18241889), Charles Dickens (1812-1870) y Mary Elizabeth Braddon (1835-1915). En el caso de la traducción de Marido y mujer (1874) de Wilkie Collins, la versión española quedó reducida al máximo; se resumió la novela inglesa y se filtraron aquellos párrafos que planteaban problemas de equivalencia formal. Sin embargo, la escritora incluyó el prólogo a la obra, donde Collins arremete contra el sistema legal británico de la época que no permitía el derecho de la mujer a la propiedad privada, aunque eliminó partes comprometedoras ${ }^{14}$.

En cuanto a las traducciones de las obras de Mary Elizabeth Braddon, Joaquina García Balmaseda vertió al español El capitán del buitre (1889) y El fruto del mar muerto (1881). Aunque no sabemos las razones por las que quiso trasladar estas obras, lo cierto es que M.E. Braddon fue una popular escritora de la época victoriana, creadora de la novela sensacionalista y, al igual que Wilkie Collins, defendió activamente los derechos de las mujeres y abogó para que estas tuvieran

14 En el prólogo a la obra, Balmaseda incluye el comentario de Wilkie Collins en contra del sistema discriminatorio contra las mujeres de Reino Unido: «Sólo me queda por añadir que, mientras escribo estas dispone a remediar los crueles abusos que se exponen en la historia de Hester Dethridge. Existe por fin el proyecto de establecer legalmente en Inglaterra el derecho de una mujer a tener propiedades y a conservar sus ingresos. A parte de esto, la legislatura no ha hecho el menor esfuerzo, que yo sepa, por depurar las deformaciones que existen en las leyes matrimoniales de Gran Bretaña e Irlanda. Los miembros de la Comisión Real han pedido la intervención del Estado sin la menor vacilación, sin que ahora hayan recibido respuesta del Parlamento» (Collins, trad. de García Balmaseda, 1874: 3). 
más participación y atención social. También tradujo El abismo (1879) de Charles Dickens, sin duda alguna el más famoso de los novelistas ingleses del siglo XIX y uno de los intelectuales que mantuvo una postura crítica ante las instituciones más representativas de su época ${ }^{15}$.

Otra de las singularidades de las traducciones de Balmaseda está relacionada con la literatura escrita por mujeres. García Balmaseda trasladó las obras de muchas novelistas francesas, entre ellas George Sand ${ }^{16}$, Madame Lardin, Mie d'Aghonne, Solange Clésinger-Sand, Virginie Ancelot, la condesa Dash, Madame Charles Reybaud y André Léo ${ }^{17}$. Lo cierto es que la traductora vertió al español las obra de George Sand ${ }^{18}$, Madame Charles Reybaud y André Léo, escritoras que eran tachadas de librepensadoras, anticlericales y republicanas entre los lectores de la época ${ }^{19}$. Aunque Sand fue muy leída, a la vez, la figura de esta autora fue ampliamente rechazada por el sector más conservador de la época, como lo señala Luis Pegenaute:

La crítica más tradicional la asocia -al igual que Dumas, Balzac o Sue- con los nuevos y nocivos aires del Romanticismo, con el polémico género de la novela, con la avalancha de autores franceses que vienen a contaminar nuestra patria, corrompiendo la moralidad y las costumbres, otorgándole a la mujer un papel que no le corresponde y desvirtuando los sacrosantos ideales religiosos sobre el matrimonio (2004: 352).

15 El abismo fue escrito por Charles Dickens y Wilkie Collins y apareció por entregas en el periódico All Year Round en 1867. Hoy en día se ha revisado y cambiado la traducción del título por Callejón sin salida. Balmaseda fue la primera en traducir la obra y posteriormente se editó en la colección Biblioteca Moral, Científica y Literaria, aunque como era común en la época, no se indicó el nombre del traductor.

16 Balmaseda tradujo cuatro obras de George Sand (1804-1876): El marqués de Villemer (1861), Las damas verdes (1863), Cesarina Dietrich (1871) y Flammarande (1878).

17 Helena Establier Pérez ha señalado que: «Las otras escritoras citadas fueron tan prolíficas como renombradas en su tiempo, y aunque todas ellas aprovechan sus obras para visibilizar a su propio género, lo cierto es que representan modalidades diferentes dentro de la novela femenina de la segunda mitad del siglo XIX» (2015: 78).

18 George Sand (1804-1876), se llamaba en realidad Aurore Dupin. Casada con el barón Casimir Dudevant, pronto se separó de él, y se convirtió en el paradigma de la mujer independiente, capaz de organizar su vida siguiendo sus inclinaciones y sus impulsos. Por esta causa el escándalo la acompañó siempre. Eso no le impidió consagrarse por entero a la escritura; dejando un centenar de obras, todas ellas muy populares durante el siglo XIX.

19 Carmen Ramírez Gómez refiriéndose a la disparidad de escritoras que traduce Balmaseda señala: «Las tres escritoras representan una misma opción estética (la novela popular costumbrista e histórica), pero contrapuestos discursos ideológicos (feminismo de distinta intensidad estética y ética)» (2015: 63). 
En relación a las traducciones de Sand por Balmaseda, hay que reconocer que sus versiones ofrecen muchas modificaciones, cuyo fin consiste en españolizar el texto y acomodarlo a la cultura meta, ya que como bien ha señalado Carmen Ramírez Gómez: «Las constantes intervenciones subordinan a menudo performances estructurales y poéticas a las variaciones arbitrarias, razones materiales o morales, hasta tal punto que entrega finalmente al lector un texto modificado de la obra, no siempre conforme a la letra original» (2016: 398). De esta manera, al traducir estos relatos, la autora trae a la luz escenas amorosas, pero a la vez, elimina aquellas que puedan causar escándalo y se acomoda a las normas morales y religiosas de la España de su tiempo. Aunque se mantiene fiel a los textos, Balmaseda pierde su transparencia para dejar sentir su romanticismo moderado y respetuoso con las estructuras tradicionales propias de la época.

\section{Conclusiones}

Aunque la mayoría de los críticos consideran a Joaquina García Balmaseda como periodista y escritora, no podemos olvidar su faceta como traductora durante más de dos décadas. Balmaseda se dedicó a verter al español obras extranjeras, muchas de ellas de tono didáctico y moral y, en su mayoría, francesas. Destaca así la inmediatez con la que traduce las obras, lo dificultoso que resultaba trasladar y acortar obras de grandes dimensiones para acomodarlas a la prensa. También la preocupación comercial podría explicar ciertos cambios y recortes introducidos por la traductora, los cuales confirman que el principal objetivo de las publicaciones no era el de ofrecer el texto original en su forma más fidedigna, sino simplemente captar la atención de los lectores y adecuarse a los estándares morales de la época. Las supresiones o modificaciones afectan a cuestiones políticas, morales y religiosas, a expresiones contrarias a las buenas costumbres, al matrimonio, la familia o los valores de la patria. En cuanto a los aspectos religiosos, García Balmaseda intenta que los personajes trazados por escritores como Wilkie Collins y George Sand, no se alejen peligrosamente de la tradición católica.

En todo caso, la traducción literaria tenía unas connotaciones muy especiales para ella: era un instrumento importante para el logro de sus aspiraciones y una forma de adoptar nuevas formas literarias, sobre todo, francesas. Además, estas traslaciones le permitieron vivir de su pluma, en una época en la que era tan difícil subsistir solamente con sus novelas y artículos periodísticos. En definitiva, puede decirse que las obras y los autores traducidos por García Balmaseda reflejan sus afinidades estéticas, y confirman que estas versiones desempeñaron un papel muy relevante en su producción literaria. 


\section{Bibliografía}

Botrel, J. F. (2009): «Paul Féval». En: Francisco Lafarga, Luis Pegenaute (eds.), Diccionario bistórico de la traducción en España. Madrid: Gredos, 386-387.

Botrel, J. F. (1996): «La literatura popular: tradición, dependencia e innovación». En: Hipólito Escolar (ed.), Historia ilustrada del libro español. La edición moderna. Siglos XIX y XX. Madrid: Fundación Germán Sánchez Ruipérez, 239-271.

Collins, W. (1874): Marido y mujer. J. García Balmaseda (trad.). Madrid: Imprenta de La Correspondencia de España.

Collins, W. (1876). La muerta viva. J. García Balmaseda (trad.). Madrid: Imprenta de La Correspondencia de España.

Collins, W. (1878). ¡Pobre Lucila! J. García Balmaseda (trad.). Madrid: Imprenta de La Correspondencia de España.

Collins, W. (2009): Poor Miss Finch. The Project Gutenberg Ebook: https:// www.gutenberg.org/files/3632/3632-h/3632-h.htm (26-10-2021).

Collins, W. (2016): Man and Wife. The Project Gutenberg Ebook: https://www. gutenberg.org/cache/epub/1586/pg1586-images.html (04-05-2021).

Collins, W. $\left(2016^{2}\right)$ : The New Magdalen. The Project Gutenberg Ebook: https://www.gutenberg.org/files/1623/(09-05-2021).

Crespo Hidalgo, J. (2007): «Políticas de traducción en la España del siglo XIX». En: Juan Jesús Zaro (ed.), Traductores y traducciones de literatura y ensayo (1835-1919). Granada: Editorial Comares, 45-72.

De Andrés Argente, J. (2007): «Oficio de escritoras». En: Asunción Bernárdez Rodal (ed.), Escritoras y periodistas en Madrid (1876-1926). Madrid: Dirección General de Igualdad de Oportunidades, 37-82.

Establier Pérez, H. (2015): «La literatura popular europea en la España decimonónica: las traducciones de Joaquina García Balmaseda para La Correspondencia de España (1861-1864)». En: Francisco Lafarga, Luis Pegenaute (eds.), Creación y traducción en la España del siglo XIX. Berna: Peter Lang, 69-84.

García Balmaseda, J. (1860): Correo de la Moda. Album de Señoritas. Madrid: Imprenta de M. Campo Redondo.

García Balmaseda, J. (1881): «La actriz española». En: Faustina Sáez de Melgar (ed.), Las mujeres españolas, americanas y lusitanas pintadas por sí mismas. Barcelona: Juan Pons, 63-77.

García Balmaseda, J. (1880): «La lectura». El Correo de la Moda, 26, 123-124.

García Balmaseda, J. (1882): La mujer sensata. Educación de sí misma. Consejos útiles para la mujer y leyendas morales. Madrid: Imprenta de la Correspondencia. 
García Balmaseda, J. (1874): «Prólogo». En: Wilkie Collins. Marido y mujer. Madrid: Imprenta de La Correspondencia de España, 4.

Gómez-Elegido Centeno, A. M. (2014): «Joaquina García Balmaseda y su contribución periodística al universo femenino decimonónico». Arbor, 767, 1-11. http://arbor.revistas.csic.es (02-03-2021).

Hibbs, S. (2015): «La traducción como mediación cultural en el siglo XIX: reflexiones epistemológicas y metodológicas sobre una práctica compleja». En: Francisco Lafarga, Luis Pegenaute (eds.), Creación y traducción en la España del siglo XIX. Berna: Peter Lang, 197-233.

Kirkpatrick, S. (1992): Antología poética de escritoras del siglo XIX. Barcelona: Castalia.

Lafarga, F. (2005): «Sobre traductoras españolas del siglo XIX». En: Lectora, beroina, autora. La mujer en la literatura española del siglo XIX. Barcelona: PPU, 185-194. http://www.cervantesvirtual.com/ (01-03-2021).

López de Ramón, M. (2016): La construcción bistórica de la libertad de prensa. Madrid: Servicio de Publicaciones de la Universidad de Carlos III.

López Santos, M. (2015): «La novela gótica española: Entre la traducción y la adaptación». En: Francisco Lafarga, Luis Pegenaute (eds.), Creación y traducción en la España del siglo XIX. Berna: Peter Lang, 267-279.

Navas Ocaña, I. (2009): La literatura española y la crítica feminista. Madrid: Editorial Fundamentos.

Pegenaute, L. (2004): «La época romántica». En: Francisco Lafarga, Luis Pegenaute (eds.), Historia de la traducción en España. Salamanca: Editorial Dos Mundos, 321-396.

Ramírez Gómez, C. (2015): Dos traductores de letras francesas en el siglo XIX: Alberto Lista y Joaquina García Balmaseda. Barcelona: Trialba.

Ramírez Gómez, C. (2016): «La fábrica francesa de la traductora Joaquina García Balmaseda». En: Francisco Lafarga, Luis Pegenaute (eds.), Autores traductores de la España del siglo XIX. Kassel: Edition Rechenberger, 390-414.

Sáez de Melgar, F. (1869): «Ateneo artístico y literario de señoras» En: Asociación de enseñanza universal, científica, religiosa y recreativa. Madrid: Imprenta de los Sres. Rojas, 1-2. https://bibliotecavirtualmadrid.comunidad (04-03-2021).

Sánchez Llama, Í. (2001): Antología de la prensa periódica isabelina escrita por mujeres (1843-1894). Cádiz: Publicaciones de la Universidad de Cádiz.

Santa, A. (2009): «George Sand». En: Francisco Lafarga, Luis Pegenaute (eds.), Diccionario bistórico de la traducción en España. Madrid: Gredos, 1011-1013. 
Sánchez Llama, İ. (2000): Galería de escritoras isabelinas. La prensa periódica entre 1833 y 1895. Madrid: Ediciones Cátedra.

Simón de Palmer, M. C. (1991): Escritoras españolas del siglo XIX. Manual biobibliográfico. Madrid: Castalia.

Thion Soriano-Molla, D. (2015): «Joaquina García Balmaseda, notas sobre el quehacer de una traductora olvidada». En: Francisco Lafarga, Luis Pegenaute (eds.), Creación y traducción en la España del siglo XIX. Berna: Peter Lang: 437-449.

Thion Soriano-Molla, D. (2011): «Joaquina García Balmaseda: Una escritora isabelina al servicio de la mujer». Anales, 23, 381-403.

Thion Soriano-Molla, D. (2018): «Joaquina García Balmaseda». En: Diccionario bistórico de la traducción en España. http://phte.upf.edu/dhte/castellano-siglo-xix/garcia-balmaseda-joaquina/ (06-05-2021).

\section{Didacticism and morality in Joaquina García Balmaseda's translations (1837-1911)}

Keywords: translation, didacticism, censorship, female writers, female translators

Joaquina García Balmaseda (1837-1911) is a writer who is well known for her contributions to $19^{\text {th }}$ century literature and journalism. Balmaseda was an intellectual who manifested, from a young age, a double artistic vocation: literature and translation. She initiated herself into the literary world through local magazines and also through her translations. While there are many references to Balmaseda's literary production, especially her contributions to women's magazines, her work as a translator has not been thoroughly studied. The immense number of Balmaseda's renderings shows not only that translation had a great impact on her work, but also that she popularized many important writers of her time (George Sand, Paul Féval, Alexandre Dumas, Wilkie Collins, Charles Dickens, and Mary Elizabeth Braddon, among others). García Balmaseda exercised a very important role as a translator in La Correspondencia de España (1860-1925), a magazine with which she frequently collaborated. The immediacy of the works' translations stands out, as well as the difficulty that resulted from transferring and shortening long works to accommodate them to the press. In these translations, García Balmaseda included her ideological convictions that revealed longstanding traditional views. By omitting passages and modifying the plot of her translations, Balmaseda accommodated 
these novels and short stories to the "edifying literature" so typical of the age of Isabella II. In most cases, the deletions or changes affect political, moral, and religious issues, as well as expressions contrary to tradition, marriage, family, and national values.

\section{Didaktizem in moralnost v prevodnem delu Joaquine García Balmaseda (1837-1911)}

Ključne besede: prevajanje, didaktizem, cenzura, pisateljice, prevajalke

Joaquina García Balmaseda (1837-1911) je pisateljica, znana po svojih prispevkih k literaturi in novinarstvu sredi 19. stoletja. Njeno književno ustvarjanje in sodelovanje v takratnih ženskih revijah, objavljeno $\mathrm{v}$ člankih in knjižnih poglavjih, je dobro poznano, medtem ko je njeno prevajalsko delo razmeroma slabše raziskano. Balmasedini res številni prevodi dokazujejo, da je prevajanje vplivalo na njeno pisateljsko delo, hkrati pa tudi, da je pripomogla k popularizaciji najpomembnejših evropskih pisateljev tedanjega časa (na primer George Sand, Paul Féval, Alexandre Dumas, Wilkie Collins, Charles Dickens in Mary Elizabeth Brandon). Pomembna je njena vloga medkulturne posrednice, zlasti pri reviji La Correspondencia de España (1860-1925), pri kateri je tvorno sodelovala $\mathrm{z}$ objavami svojih prevodov. Posebej sta jo odlikovali hitro prevajanje del in težavno delo prenašanja in krajšanja obsežnih romanov, da so bili primerni za objavo v tisku. Vendar pa je pisateljičino književno in prevajalsko ustvarjanje zaznamovano z njenimi ideološkimi prepričanji. Pri prevodih je izpuščala dele, ki se ji niso zdeli primerni za takratnega bralca; spremenila je zgodbo in jo prilagodila tako, da je ustrezala »poučni literaturi«, tako značilni za obdobje vladavine španske kraljice Izabele II. Spremenila je predvsem politične, moralne in verske vidike ter izraze, ki so bili v nasprotju s tradicijo, zakonsko zvezo, družino ali pa domovinskimi vrednotami.

\section{María Luisa Pérez-Bernardo}

María Luisa Pérez-Bernardo es Profesora Titular en el Departamento de Idiomas Modernos de la Universidad de Dallas, Estados Unidos, donde imparte cursos de lengua, literatura y traducción. Es Licenciada en Filología Inglesa por la Universidad de Valladolid, Doctora en Filología Hispánica por la Catholic University of America; ha realizado un máster en Filología por West 
Virginia University y otro máster en Traducción Especializada por la Universidad de Córdoba, además de un certificado en Traducción por University of California, San Diego Extension. Líneas de investigación: escritoras y traductoras españolas del siglo XIX y XX, historia de la traducción en España y teoría de la traducción literaria.

Dirección:

Modern Languages and Literatures.

1845 E. Northgate Drive

Irving, TX 75062. USA.

Correo electrónico:

mperez@udallas.edu 